


$\begin{array}{lll}\sum_{\text {Child Health, University of }} & \begin{array}{l}\text { Child Health, University of } \\ \text { S. Turner }\end{array} & \begin{array}{l}\text { Aberdeen, Royal Aberdeen } \\ \text { Aberdeen, Aberdeen, UK }\end{array} \\ & \begin{array}{l}\text { Children's Hospital, } \\ \text { Aberdeen, UK, AB25 2ZG }\end{array}\end{array}$

\section{Childhood respiratory cohort studies: do they generate useful outcomes?}

\section{Educational aims}

$\odot$ To describe the strengths and limitations of cohort studies.

$\odot$ To give insight into the likely magnitude of effect of exposures on asthma causation.

$\odot$ To summarise the relative weight of predictors of asthma prognosis.

$\odot$ To describe results from cohort studies where interventions were made.

\section{Summary}

Cohort studies give insight into the evolution of respiratory disease over time and provide a low level of evidence for causation. The initial pioneering cohort studies in which symptoms and/or exposures were captured in early life and related to respiratory outcome in later life are now part of a large family which is diverse in age and exposures; however, asthma remains a fairly constant outcome.

This article aims to first describe the strengths and weaknesses of the various asthma cohort studies. Thereafter, the article aims to describe the insight that cohort studies have given into asthma causation, with a focus on relative magnitude of effect, and also to describe the relative weight of factors identified in cohort studies as predictors of persisting asthma symptoms. It is clear that many factors are implicated in asthma causation; in isolation, each exerts a rather modest positive of negative effect on causation, but are likely to be acting in combination and modifying each other's relative risk. There is no single "good" predictor of asthma outcome, but the coexistence of parental asthma/ atopy in a child with at least three episodes of wheeze by their third birthday indicates a high relative risk for asthma at 11-13 years of age. There remains no cure for asthma and the next step needs to apply what cohort studies have taught us to intervention studies where several exposures are modified in at risk individuals during the first year of life.
Statement of interest None declared.

HERMES syllabus link: modules B.1.1, F.3, I.1 


\section{Introduction}

For the purpose of this review, a cohort study is defined as an observational study for which measurements made at one point in time are related to a future outcome for a given individual. The focus of this review is asthma. The early origins of respiratory morbidity are now well described and this is thanks to more than 50 years of hard work. Initially, respiratory questions were included among many other non-respiratory outcomes in large cohorts [1, 2]. Almost 30 years ago, the first cohorts specifically designed to observe the onset of respiratory symptoms were established and some included physiological measurements in early infancy [3-5]. A review of 18 European asthma birth cohort studies which were mostly recruited during the 1990 s concluded that, despite studies evolving independently, there were consistent methodologies being applied across centres such that it was valid to combined results from these cohorts [6]; this observation suggests that a standard framework for an asthma cohort study has been established following the pioneering studies and adopted by the international research community. At present, there are approximately one hundred cohort studies around the world which are wholly or partly designed to relate early events to later respiratory morbidity. Figure 1 places some cohort studies on a world map. Given the large number of studies and long follow up of the pioneering cohorts, it is timely to ask the question: what knowledge has arisen from asthma cohort studies? What has previously been concluded is that respiratory symptoms often start in infancy, exposures during the first year of life appear to be important to later asthma outcome and that there are different patterns of wheeze within a population [7]. The aims are to 1) explore the strengths and limitations of cohort studies; 2) discuss what the early exposures may be and what magnitude of effect they have; 3) identify factors predictive of asthma outcomes which have arisen from cohort studies; and 4) summarise results of intervention studies.

\section{Strengths and limitations of cohort studies}

Given that there are so many different cohorts it is inevitable that there is a wide spectrum of study design (table 1). Variability in study design reflects lessons learnt from previous studies, advances in methods of assessment and also ethical considerations. The perfect study would follow up several thousand individuals from conception to grave and, during that time, assess all genetic variations

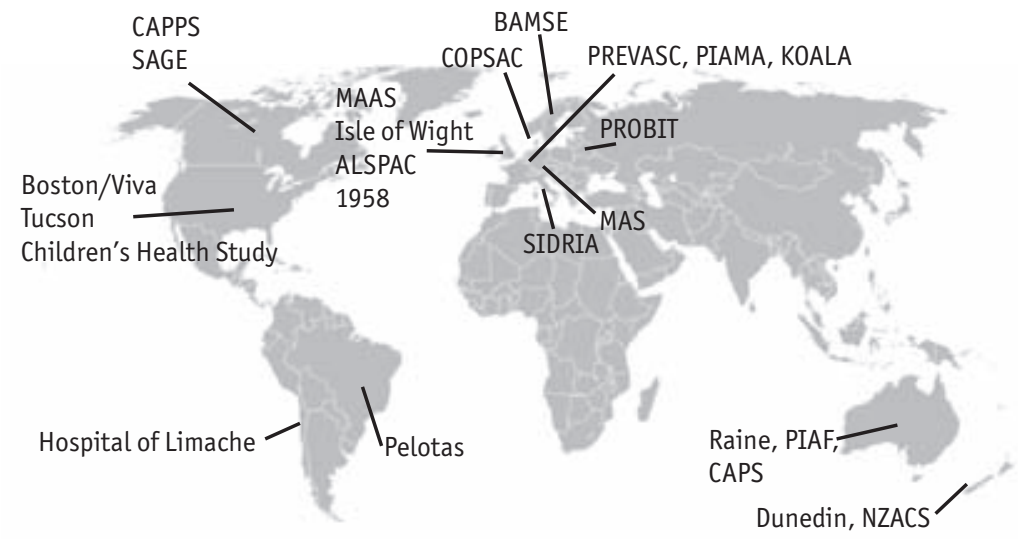

Figure 1

A map of the world showing the location of many cohort studies (including intervention studies). ALSPAC: Avon Longitudinal Study of Parents and Children; BAMSE: Children, Allergy, Milieu, Stockholm, Epidemiological survey; CAPPS: Canadian Asthma Primary Prevention Study; CAPS: Childhood Asthma Prevention Study; COPSAC: Copenhagen Prospective Study on Asthma in Childhood; KOALA: Child, Parent and Health; Lifestyle and Genetic Constitution; MAAS: Manchester Asthma and Allergy Study; MAS: German Multicentre Asthma Study; NZACS: New Zealand Asthma and Allergy Cohort Study; PIAMA: Prevention and Incidence of Mite Allergy; PIAF: Perth Infant Asthma Follow-up; PREVASC: Prevention of Asthma in Children; PROBIT: Promotion of Breastfeeding Intervention Trial; SAGE: Study of Asthma Genes and the Environment; SIDRIA: Italian Studies of Respiratory Disorders in Childhood and the Environment. 
Table 1 Differences between the designs of asthma cohort studies. In one study [11] the majority of study participants were from an unselected population but additionally, an intervention given to high risk infants was nested within the study design

\begin{tabular}{ll} 
Category & Examples \\
\hline Age at first data & Pre conception cohorts [4], Birth cohorts [1], Childhood cohorts [12] \\
\hline Inclusion criteria & $\begin{array}{l}\text { Unselected cohorts [5, 11, 13-16], inclusion of "high risk infants" (e.g. at } \\
\text { least one parent with asthma) [11, 17], inclusion of only patients with } \\
\text { asthma [12] }\end{array}$ \\
\hline Respiratory specific? & $\begin{array}{l}\text { Respiratory and non-respiratory outcomes measured [1, 2], Respiratory/ } \\
\text { allergy specific [3, 4] }\end{array}$ \\
\hline Exposure & $\begin{array}{l}\text { Allergen exposure [11], Ambient air quality [18], Breast feeding [19], } \\
\text { Maternal diet [20], Maternal illness during pregnancy [21], Smoking [22] }\end{array}$
\end{tabular}

and environmental exposures and relate these to robust indices of asthma. Life is not perfect and strengths and weaknesses of cohort studies are displayed in table 2. The practical challenges of participant recruitment and retention and limitation of finances often mean that most studies are only able to focus on one exposure/outcome; unfortunately asthma is a complex disease in which more than one gene or environmental exposure are implicated in causation. One limitation to cohort studies is that results may take many years to emerge and may not be relevant to current practice; for example, is it fair to extrapolate to children in 2012 the results from participants in the 1958 cohort who were assessed as children? People who come forward to participate in respiratory studies are not always typical of the general population [8], so results may not necessarily be generalisable even with low rates of drop out. However, drop out of participants is inevitable and introduces bias into the remaining study population (children of smoking and less affluent parents are more likely to drop out) and also reduces a study's power to detect the presence of an association and, even more so, the absence of an association. Further limitations are that once a study is underway it is very hard to retrospectively include additional exposures and that the associations described do not necessarily equate to causation. Finally, the flaw in every asthma study is that there is no gold standard test or definition for asthma,

Table 2. Strengths and weaknesses of asthma cohort studies

\begin{tabular}{ll}
\hline Strengths & \multicolumn{1}{c}{ Limitations } \\
\hline Prospective data collection (no recall bias) & $\begin{array}{l}\text { Can be difficult to change study protocol, e.g. } \\
\text { retrospectively add data, change outcome }\end{array}$ \\
\hline Hypothesis driven & Still does not prove causation \\
\hline Essential for intervention studies & Recruitment of representative population \\
\hline Longitudinal analysis can reduce sample size & Drop out \\
\hline Analysis can minimise effect of drop out & Often only considers one exposure \\
\hline $\begin{array}{l}\text { Able to consider different exposures at } \\
\text { different times }\end{array}$ & Cost \\
\hline
\end{tabular}

Lack of gold standard outcome 
and different asthma definitions can invalidate direct comparison between studies. Given the lack of a gold standard phenotype for asthma and heterogeneity in genetic and environmental characteristics across the world's population, it is perhaps not surprising that different studies yield apparently inconsistent results; one example of this is the relationship between breast feeding and asthma which is positive in some studies but negative in others [9]. One alternative to the typical cohort is to use routinely acquired data and undertake "real world" whole population studies; while this is not without another series of limitations it has been advocated [10] and already used in Scandinavian countries.

\section{What are the risk factors for asthma? Can we predict who will get asthma?}

Asthma is a classical complex disease in which a series of genetic and environmental factors interact, often at critical stages of development. As for all complex diseases (e.g. cancer, ischaemic heart disease), the risk for developing asthma can be described for the population but not for the individual. A child at a high risk for developing asthma may never develop symptoms and, conversely, a child with no apparent risk factors may develop troublesome symptoms. It is not possible to predict who will and will not develop asthma; instead, what can be done instead is describe the relative risk (table 3). The truly novel insight which cohort studies have provided is the ability to identify when these factors become important. Many factors appear to be acting early in life, some even before birth, but the presence of adultonset asthma is evidence that symptoms can appear at any time during life. To add a further dimension to the model, there are almost certainly interactions between factors, e.g. family history of atopy and breast feeding [19], atopy and early viral infection [23], and parental atopy and smoking [24].

\section{What is the evidence that factors are acting early?}

Cohort studies for which physiological measurements were made in asymptomatic infants or young children who were then followed up have demonstrated that the hallmarks of childhood asthma are present before the onset of symptoms; these features include atopy [31], reduced lung function [4], bronchial hyper-reactivity [13] and airway eosinophilia [32]. Further evidence that early influences are

Table 3 Results from systematic reviews relating relative risk for asthma to factors. This list is not intended to be exhaustive but serves to illustrate that each factor has a relatively modest association in isolation. What is unknown is whether relative risks are additive or multiplicative when more than one factor is present for an individual

\begin{tabular}{|c|c|c|}
\hline Risk factor for developing childhood asthma & Relative risk $[95 \% \mathrm{Cl}]$ & Comment \\
\hline Paternal asthma [26] & $2.44[2.14-2.79]$ & \\
\hline Atopy [27] & 1.5 to 4.8 & \\
\hline Antenatal paracetamol exposure [28] & $1.28[1.16-41]$ & \\
\hline Dog exposure [29] & $1.14[1.01-1.29]$ & $1.39[1.00,1.95]$ for any furry pet \\
\hline Cat exposure [29] & $0.72[0.55-0.93]$ & \\
\hline Breast feeding [19] & $0.70[0.60-0.81]$ & Lower in atopic families (OR 0.52 ) \\
\hline High maternal vitamin E during pregnancy [20] & $0.68[0.52-0.88]$ & Wheezing outcomes not asthma \\
\hline Mediterranean diet during pregnancy [20] & $0.22[0.08-0.58]$ & Wheezing outcomes not asthma \\
\hline
\end{tabular}


important to asthma is that reduced fetal size at ten weeks gestation has been linked to increased respiratory morbidity in 10-yr-olds [33]. There are at least two implications for these findings. First, for many children (and adults), asthma develops in early life and second there is a "pre-asthmatic" stage during which intervention might influence asthma outcome. Table 3 summarises some of the early factors associated with asthma and their possible magnitude of effect.

\section{Which factors are acting early?}

\section{Genetic factors}

Most asthma cohort studies have collected DNA from participants and, as a consequence, many genetic variations associated with asthma have been identified from studies of candidate genes and, more recently, genome-wide association studies. Cohort studies have the potential to explore the hypothesis that the relationship between genetic factors and asthma changes over time but there is very little evidence to support this. What is known is that a parental history of asthma is associated with increased risk for childhood asthma [26], and this suggests that shared genetic and environmental factors are important to asthma causation. Twin studies have demonstrated how concordance for asthma in monozygotic twins is higher than for dizygotic twins (approximately 20 and $5 \%$ respectively) [34]. These twin studies provide evidence that shared genetic factors are associated with asthma regardless of shared environmental exposures and, furthermore, are able to quantify the genetic contribution to asthma within families as up to $70 \%$ [34]. There is no single asthma gene, rather a small number of genetic factors, each of which making a modest contribution to asthma risk. A recent study has described five genetic factors linked to asthma in a large European dataset which included many children [35]. This study is noteworthy in identifying a genetic variant (ORMDL3) with childhood onset asthma suggesting that this genetic susceptibility is particularly apparent early in life [35].

\section{Westernised lifestyle}

The International Study of Asthma and Allergy in Childhood has demonstrated considerable variability in prevalence of childhood asthma across the world [36]. Asthma prevalence is highest in more affluent countries with evidence of increasing prevalence in developing countries [36]. The higher prevalence of asthma among children in West Germany (6\%) when compared with East Germany (4\%) in the early 1990 save some insight into the association between a "Westernised lifestyle" and childhood asthma; assuming a similar genetic pedigree of children in East and West Germany, the different asthma prevalences must be explained by environment. Children in China have lower prevalence of asthma symptoms compared with those in Hong Kong and those who migrate from China to "Westernised" Hong Kong after the age of 2 years still retain the apparent protective effect of their early environment against asthma [37].

\section{Dietary factors}

Breast feeding is usually associated with reduced risk for asthma but this relationship is not replicated in all studies. Cohort studies have demonstrated that there is an overall protective effect of breast feeding on asthma development [19]. Adults and children with asthma have, in some studies, been found to have reduced intake of vitamins $A, C$ and $E$ but intervention studies in adults have demonstrated how vitamin supplementation leads to no meaningful improvement in asthma outcomes [38]. The dietary hypothesis proposes that an excess of dietary oxidant or lack of dietary antioxidants in maternal diet during pregnancy leads to increased asthma [38]. This hypothesis has been tested in a number of populations and the published studies support the concept of maternal nutrition during pregnancy being important to early childhood asthma. This review has considered only nutrients where consistent findings have arisen from more than one high-quality cohort study or where an intervention study has been completed. Children of mothers with reduced vitamin $D$ intake are at increased risk for wheeze [20]. Reduced maternal vitamin E during pregnancy has also been linked to increased adverse asthma outcomes in 5-yr olds including symptoms and lung function [20]. Increased N6 polyunsaturated fatty acids (PUFA) and reduced $\mathrm{N}_{3}$ PUFA have been implicated in atopy causation but there is little evidence to determine whether these lipids are important in asthma causation. It seems improbable that a single nutrient insufficiency or excess determines asthma risk; factors such 
as vitamins $C, D$, and $E$ may be merely markers of a "good" diet. What is required is an intervention study to determine whether these associations are causative.

\section{Early respiratory infection}

Cohort studies consistently demonstrate that bronchiolitis is a risk factor for subsequent asthma symptoms but this association is transient in cohorts recruited from the community whereas one cohort recruited from infants admitted with respiratory syncitial virus (RSV) reported increased asthma at 18 years of age [39]. A cohort in Australia provided evidence that early infection with RSV or rhinovirus is associated with later asthma symptoms but only in those with co-existent atopy [23].

\section{Exposure to tobacco smoke}

Children exposed to secondhand smoke are at increased risk for many respiratory outcomes including asthma. Since many children exposed to SHS were exposed to products of tobacco smoke in utero it is difficult to determine whether antenatal or postnatal exposure is more important to asthma causation. What is clear is that the relationship between exposure and asthma is not straightforward. A Finnish cohort study has demonstrated an interaction between parental atopy and parental smoking for asthma [24]. Cohort studies have demonstrated that genes coding for airway anti-oxidant defences appear to be important to the presence of symptoms [40] and physiological measurements [41] in individuals whose mothers smoked during pregnancy.

\section{Inhaled particles}

Further evidence of interactions between environmental exposures and genetic factors resulting in childhood asthma comes from a UK cohort where environmental exposure to lipopolysaccharide (LPS) was related to risk for wheeze at age 5 years. When the whole population was considered, there was no association; but when subdivided by a gene important to cellular immune recognition of LPS, those children with the $\mathrm{CC}$ genotype subgroup of the $\mathrm{CD} 14$ gene were at increased risk for wheeze with increasing exposure (odds ratio approximately 1.4) [42]. Early exposure (mostly by inhalation) to cat and dog allergen may respectively increase and decrease later risk for asthma [29].

\section{Atopy}

Asthma is primarily a respiratory condition but is associated with atopy in many cases. Although not primarily an allergic condition, asthma is closely related to atopy but this relationship is inconsistent since many allergic children are not asthmatic and one quarter of asthmatic children are non-allergic [27]. Risk factors for atopy are often different to those for asthma, e.g. birth order for atopy, exposure to secondhand smoke for asthma and genetic factors associated with atopy and typically not linked with asthma [35]. Atopy has been estimated to explain approximately $38 \%$ of asthma cases (range 25-63\%) [27]. One explanation to this apparently confused relationship between atopy and asthma is that atopy is considered as a bivariate outcome but atopy should be considered a continuous outcome (for example like forced expiratory volume in $1 \mathrm{~s})$ since type-specific immunoglobulin (Ig)E comes with a range of values in any population. Age at onset of atopy is very important, cohort studies have demonstrated that onset of atopy before school age is associated with more severe asthma outcomes [43] and atopy which develops after age 5 years is probably not relevant to asthma causation. One paradigm which explains the relationship between atopy and asthma is that for an individual with an underlying airway abnormality (possibly of airway epithelial cell function) to develop symptoms they either need a markedly abnormal airway abnormality alone or a modest abnormality plus modest atopy or perhaps a minor airway abnormality plus severe atopy.

\section{Who grows out of asthma and can we predict prognosis? Will my child grow out of their asthma?}

The prospective collection of questionnaire and physiological data over time allows cohort studies the luxury of hindsight and some have developed algorithms that predict outcomes of early wheeze. Unfortunately, whilst useful on a whole-population basis, these algorithms do lack precision. The three most consistent indices of persisting wheeze are frequent early wheeze, parental history of asthma and early onset atopy in the child; these three factors probably correspond to airway abnormality, genetic susceptibility and atopy respectively. Table 4 summarises the relative risk for different risk factors described in cohort 
studies. Due to the challenge in measuring respiratory physiology in young children, all but one algorithm combines factors obtained from the history, some also include allergy testing [44] and one also includes allergen exposure [45]. At the time of writing, a single study has related lung function and nitric oxide in $4 \mathrm{yr}$ olds to later symptoms and found limited evidence that these measurements may be useful [46].

\section{Can we prevent asthma? What can I do to stop my other children from getting asthma?}

There is no cure for asthma; however, a number of centres have introduced interventions aimed at reducing the risk for developing asthma. These pioneering studies have given important insight into asthma aetiology during infancy and highlighted the complexities and pitfalls in trying to prevent asthma. Single interventions have proven disappointing whereas multiple interventions have shown evidence in reducing asthma symptoms in childhood.

In Manchester, UK, a birth cohort of 251 infants at high risk for allergy was randomised to an intervention which very effectively removed house dust mites (HDM) from their environment for the first year [50]. At age 3 years, the intervention group were somewhat unexpectedly at increased risk for HDM sensitisation (OR 2.9; 95\% $\mathrm{Cl}$ 1.0-8.0). The intervention was associated with a reduction in airway resistance of approximately $20 \%$. Outcomes beyond 3 years have not been reported despite the cohort having been followed up past age 5 years, so it is possible that the outcomes at 3 years did not persist. What this study demonstrates is that an apparently simple intervention can be far from simple. By reducing HDM exposure, there was an increase in IgE sensitisation but an unexpected improvement in lung function, the latter may have been due to exposure to an adverse exposure, e.g. lipopolysaccharide, which was inadvertently reduced by the intervention. A second intervention study in the Netherlands introduced the single intervention of HDM reduction and the intervention was associated with reduced recurrent wheeze during infancy but not at 2 years of age [11].

A study by Canadian researchers in Belarus randomised mothers attending 31 maternity hospitals to an educational intervention aimed at prolonging extended breast feeding. In total,

Table 4 Summarising relative weight placed on measured variables in children aged 3 years for asthma at 11-13 years (7-8 years for PIAMA)

\begin{tabular}{|c|c|c|c|c|c|}
\hline $\begin{array}{l}\text { Early recurrent } \\
\text { wheeze }\end{array}$ & +++ & & +++ & 1.8 & 3.9 \\
\hline $\begin{array}{l}\text { Parental asthma/ } \\
\text { atopy }\end{array}$ & +++ & 2.3 & & 8.3 & 1.9 \\
\hline $\begin{array}{l}\text { Early IgE } \\
\text { sensitisation }\end{array}$ & ++ & 5.7 & & 4.7 & \\
\hline Rhinitis & ++ & 0.4 & & & 1.6 \\
\hline $\begin{array}{l}\text { Recurrent chest } \\
\text { infection }\end{array}$ & & 2.0 & & & 1.8 \\
\hline
\end{tabular}




\section{Educational questions}

1) Name three ways in which respiratory cohort study design may differ from one another.

2) Name four strengths and four weaknesses in cohort studies.

3) Name four factors associated with increased risk for asthma and four associated with reduced risk for asthma.

4) Name four factors associated with increased risk for early wheeze persisting.
17,046 infants participated. After 1 year, mothers who had received the intervention had breastfed for longer and exclusively breastfed for longer compared with controls. Infants of mother who received the intervention were less likely to have diarrhoeal illnesses and eczema. At 6 years of age, those in the intervention group were more likely to be skin-prick positive (OR 2.0; $95 \% \mathrm{Cl}$ 1.1-3.4) but there was no increase or decrease in asthma symptoms [51].

A birth cohort of 120 infants at high risk for developing allergy was recruited in the Isle of Wight, UK. Infants were randomised to a complex allergen-avoidance intervention aimed at reducing exposure to HDM and cow's milk. At 8 years of age, individuals who received the intervention were less likely to have current wheeze (OR 0.3; 95\% Cl 0.1-1.0) and atopy (OR $0.2 ; 95 \% \mathrm{Cl}$ 0.1-0.6) [52].

The Childhood Asthma Prevention Study (CAPS) in Sydney, Australia, sought to reduce the risk of asthma developing in 616 infants at higher risk for asthma. The intervention here was either HDM reduction or dietary supplementation with omega-3 and reduction of omega- 6 fatty acids or both or neither. At 3 years of age, those children who had developed atopy but who had dietary supplementation had $10.0 \%(95 \% \mathrm{Cl} 3.7-16.4)$ reduction in the prevalence of cough. There was a $7.2 \%$ (95\% Cl 10.11-14.3) reduction in sensitisation to HDM in the active allergen avoidance group $(p=0.05$; number needed to treat: 14) [53]. There are no published outcomes beyond 3 years despite the cohort being recruited in the late 1990s.

A randomised-controlled study tested the effect of a multifaceted intervention programme on the primary prevention of asthma in high-risk infants in Canada. Here, 545 infants with at least one parent with asthma were randomised to a complex intervention including four components: 1) reduction of house dust mite exposure; 2) reduction of exposure to pets; 3 ) reduced exposure to environmental tobacco smoke; and 4) avoidance of cow's milk protein and delayed weaning. At 7 years of age, 469 children were followed up and the intervention was associated with a reduced risk for diagnosed asthma of $0.44(95 \% \mathrm{Cl}, 0.25-$ 0.79), the intervention was not associated with reduced atopy or BHR so the underlying mechanism is not clear but was not by delaying onset of atopy [17].

The outcomes of these studies can be summarised thus:

1. Complex interventions, i.e. where more than one exposure is altered, are more likely to be effective when compared with simple interventions

2. A single intervention may influence more than one exposure

3. Many studies were in small cohorts and follow-up has not been long enough

\section{Conclusions and future research}

Cohort studies continue to give insight into the timing of early exposures on asthma causation and their magnitude of effect. Figure 1 demonstrates that these studies are mostly restricted to the developed world and similar studies would be welcomed in Asia and Africa. Given the changing nature of our environment and lifestyle, there is justification for more cohort studies to be recruited and these should carefully consider their study design to reflect clinically relevant questions. Whole population studies in Finland and Sweden validate the use of routinely acquired data as part of "real-world" studies and these have benefits of yielding rapid results at low cost. Genetic variations, sex, age and socioeconomic status are all associated with altered risk for asthma but are not modifiable; however, intervention studies can be designed to modify what can be changed, i.e. lifestyle, to prevent asthma developing.

\section{Acknowledgements}

The author would like to acknowledge the invaluable contribution made by Prof. C. Kuehni in the design of this review

\section{REFERENCES}

1. Power C, Elliott J. Cohort profile: 1958 British birth cohort (National Child Development Study). Int J Epidemiol 2006; 35: 34-41.

2. Edwards CA, Osman LM, Godden DJ, et al. Wheezy bronchitis in childhood: a distinct clinical entity with lifelong significance? Chest 2003; 124: 18-24.
3. Martinez FD, Wright AL, Taussig LM, et al. Asthma and wheezing in the first six years of life. The Group Health Medical Associates. N Engl J Med 1995; 332: 133-138.

4. Turner SW, Palmer LJ, Rye PJ, et al. The relationship between infant airway function, childhood airway 
responsiveness, and asthma. Am J Respir Crit Care Med 2004; 169: 921-927.

5. Sears MR, Jones DT, Silva PA, et al. Asthma in seven year old children: a report from the Dunedin Multidisciplinary Child Development Study. NZ Med J 1982; 95: 533-536.

6. Keil T, Kulig M, Simpson A, et al. European birth cohort studies on asthma and atopic diseases: I. Comparison of study designs - a GALEN initiative. Allergy 2006; 61: 221-228.

7. Wright AL, Taussig LM. Lessons from long-term cohort studies. Childhood asthma. Eur Respir J 1998; 27 Suppl.

8. Herland K, Akselsen JP, Skjonsberg $\mathrm{OH}$, et al. How representative are clinical study patients with asthma or COPD for a larger "real life" population of patients with obstructive lung disease? Respir Med 2005; 99: 11-19.

9. Brew BK, Kull I, Garden F, et al. Breastfeeding, asthma, and allergy: a tale of two cities. Pediatr Allergy Immunol 2011 [Epub ahead of print: DOI: 10.1111/j.1399-3038.2011.01229.x].

10. Holgate $\mathrm{S}$, Bisgaard H, Bjermer L, et al. The Brussels Declaration: the need for change in asthma management. Eur Respir J 2008; 32: 1433-1442.

11. Brunekreef B, Smit J, de Jongste J, et al. The prevention and incidence of asthma and mite allergy (PIAMA) birth cohort study: design and first results. Pediatr Allergy Immunol 2002; 15: 55-60.

12. Phelan PD, Robertson CF, Olinsky A. The Melbourne Asthma Study: 1964-1999. J Allergy Clin Immunol 2002; 109: 189-194.

13. Turner SW, Young S, Goldblatt I, et al. Childhood asthma and increased airway responsiveness: a relationship that begins in infancy. Am J Respir Crit Care Med 2009; 179: 98-104.

14. Henderson J, Granell R, Heron J, et al. Associations of wheezing phenotypes in the first 6 years of life with atopy, lung function and airway responsiveness in mid-childhood. Thorax 2008; 63: 974-980.

15. Devereux G, Turner SW, Craig LC, et al. Low maternal vitamin $\mathrm{E}$ intake during pregnancy is associated with asthma in 5-year-old children. Am J Respir Crit Care Med 2006; 174: 499-507.

16. Oddy WH, Sherriff JL, de Klerk NH, et al. The relation of breastfeeding and body mass index to asthma and atopy in children: a prospective cohort study to age 6 years. Am J Public Health 2004; 94: 1531-1537.

17. Chan-Yeung M, Ferguson A, Watson W, et al. The Canadian Childhood Asthma Primary Prevention Study: outcomes at 7 years of age. J Allergy Clin Immunol 2005; 116: 49-55.

18. Gauderman WJ, Avol E, Gilliland F, et al. The effect of air pollution on lung development from 10 to 18 years of age. N Engl J Med 2004; 351: 1057-1067.

19. Gdalevich M, Mimouni D, Mimouni M. Breastfeeding and the risk of bronchial asthma in childhood: a systematic review with meta-analysis of prospective studies. J Pediatr 2001; 139: 261-266.

20. Nurmatov U, Devereux G, Sheikh A. Nutrients and foods for the primary prevention of asthma and allergy: systematic review and meta-analysis. J Allergy Clin Immunol 2011; 127: 724-733.

21. Rusconi F, Galassi C, Forastiere F, et al. Maternal complications and procedures in pregnancy and at birth and wheezing phenotypes in children. Am J Respir Crit Care Med 2007; 175: 16-21.

22. Tager IB, Ngo L, Hanrahan JP. Maternal smoking during pregnancy. Effects on lung function during the first 18 months of life. Am J Respir Crit Care Med 1995; 152: $977-983$.

23. Kusel MM, de Klerk NH, Kebadze T, et al. Early-life respiratory viral infections, atopic sensitization, and risk of subsequent development of persistent asthma. J Allergy Clin Immunol 2007; 119: 1105-1110.

24. Jaakkola JJ, Nafstad P, Magnus P. Environmental tobacco smoke, parental atopy, and childhood asthma. Envir Health Perspect 2001; 109: 579-582.

25. Strachan DP, Cook DG. Health effects of passive smoking. 6. Parental smoking and childhood asthma: longitudinal and case-control studies. Thorax 1998; 53: 204-212.

26. Lim RH, Kobzik L, Dahl M. Risk for asthma in offspring of asthmatic mothers versus fathers: a metaanalysis. PLOS ONE 2010; 5: doi:10.1371/journal. pone.0010134.

27. Pearce N, Pekkanen J, Beasley R. How much asthma is really attributable to atopy? Thorax 1999; 54: 268-272.

28. Etminan M, Sadatsafavi M, Jafari S, et al. Acetaminophen use and the risk of asthma in children and adults: a systematic review and metaanalysis. Chest 2009; 136: 1316-1323.

29. Takkouche B, Gonzalez-Barcala FJ, Etminan M, et al. Exposure to furry pets and the risk of asthma and allergic rhinitis: a meta-analysis. Allergy 2008; 63: 857-864.

30. Tischer C, Chen C-M, Heinrich J. Association between domestic mould and mould components, and asthma and allergy in children: a systematic review. Eur Respir J 2011; 38: 812-824.

31. Sly PD, Boner AL, Bjorksten B, et al. Early identification of atopy in the prediction of persistent asthma in children. Lancet 2008; 372: 1100-1106.

32. Pohunek P, Warner JO, Turzikova J, et al. Markers of eosinophilic inflammation and tissue re-modelling in children before clinically diagnosed bronchial asthma. Pediatr Allergy Immunol 2005; 16: 43-51.

33. Turner S, Prabhu N, Danielian P, et al. First and second trimester fetal size and asthma outcomes at age ten years. Am J Respir Crit Care Med 2011; 184: 407-413.

34. Los H, Postmus PE, Boomsma DI. Asthma genetics and intermediate phenotypes: a review from twin studies. Twin Research 2001; 4: 81-93.

35. Moffatt MF, Gut IG, Demenais F, et al. A large-scale, consortium-based genomewide association study of asthma. N Engl J Med 2010; 363: 1211-1221.

36. Asher MI, Montefort S, Bjorksten B, et al. Worldwide time trends in the prevalence of symptoms of asthma, allergic rhinoconjunctivitis, and eczema in childhood: ISAAC Phases One and Three repeat multicountry cross-sectional surveys. Lancet 2006; 368: 733-743.

37. Wong GW, Leung TF, Ma Y, et al. Symptoms of asthma and atopic disorders in preschool children: prevalence and risk factors. Clin Exp Allergy 2007; 37 174-179.

38. Devereux G, Seaton A. Diet as a risk factor for atopy and asthma. J Allergy Clin Immunol 2005; 115: 1109-1117.

39. Sigurs N, Aljassim F, Kjellman B, et al. Asthma and allergy patterns over 18 years after severe RSV bronchiolitis in the first year of life. Thorax 2010; 65 : 1045-1052.

40. Gilliland FD, Li YF, Dubeau L, et al. Effects of glutathione $S$-transferase $M_{1}$, maternal smoking during pregnancy, and environmental tobacco smoke on asthma and wheezing in children. Am J Respir Crit Care Med 2002; 166: 457-463.

41. Murdzoska J, Devadason SG, Khoo SK, et al. In utero smoke exposure and role of maternal and infant glutathione $\mathrm{S}$-transferase genes on airway responsiveness and lung function in infancy. Am J Respir Crit Care Med 2010; 181: 64-71.

42. Simpson A, John SL, Jury F, et al. Endotoxin exposure, $\mathrm{CD}_{14}$, and allergic disease: an interaction between genes and the environment. Am J Respir Crit Care Med 2006; 174: 386-392. 
43. Turner SW, Heaton T, Rowe J, et al. Early-onset atopy is associated with enhanced lymphocyte cytokine responses in 11-year-old children. Clin Exp All 2007; 37: 371-380.

44. Castro-Rodriguez JA, Holberg C), Wright AL, et al. A clinical index to define risk of asthma in young children with recurrent wheezing. Am J Respir Crit Care Med 2000; 162: 1403-1406.

45. Matricardi PM, Illi S, Gruber C, et al. Wheezing in childhood: incidence, longitudinal patterns and factors predicting persistence. Eur Respir J 2008; 32: 585-592.

46. Caudri D, Wijga AH, Hoekstra MO, et al. Prediction of asthma in symptomatic preschool children using exhaled nitric oxide, Rint and specific IgE. Thorax 2010; 65: 801-807.

47. Kurukulaaratchy RJ, Matthews S, Holgate ST, et al. Predicting persistent disease among children who wheeze during early life. Eur RespirJ 2003; 22: 767-77.

48. Leonardi NA, Spycher BD, Strippoli MP, et al. Validation of the Asthma Predictive Index and comparison with simpler clinical prediction rules. J Allergy Clin Immunol 2011; 127: 1466-1472.
49. Caudri D, Wijga A, CM AS, et al. Predicting the longterm prognosis of children with symptoms suggestive of asthma at preschool age. J Allergy Clin Immunol 2009; 124: 903-910.

50. Woodcock A, Lowe LA, Murray CS, et al. Early life environmental control: effect on symptoms, sensitization, and lung function at age 3 years. Am J Respir Crit Care Med 2004; 170: 433-439.

51. Kramer MS, Matush L, Vanilovich I, et al. Effect of prolonged and exclusive breast feeding on risk of allergy and asthma: cluster randomised trial. Brit Med J 2007; 335: 20 .

52. Arshad SH, Bateman B, Matthews SM. Primary prevention of asthma and atopy during childhood by allergen avoidance in infancy: a randomised controlled study. Thorax 2003; 58: 489-493.

53. Peat JK, Mihrshahi S, Kemp AS, et al. Three-year outcomes of dietary fatty acid modification and house dust mite reduction in the Childhood Asthma Prevention Study. J Allergy Clin Immunol 2004; 114: 807-813.

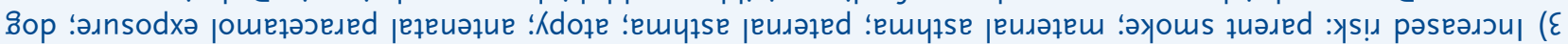

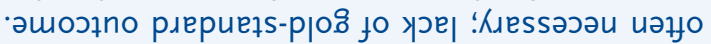

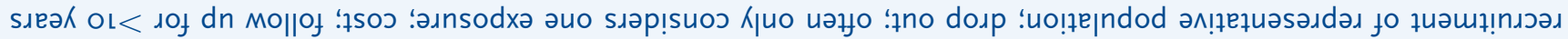

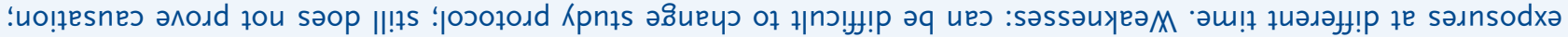

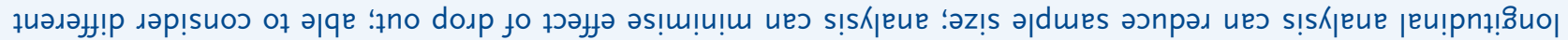

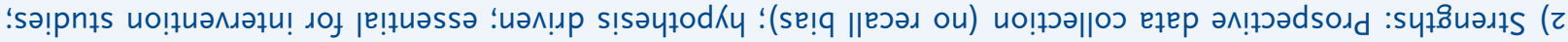

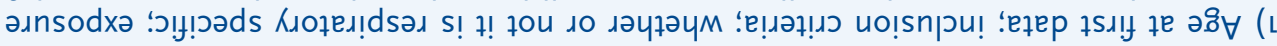

